\title{
TOWARD A SCHOLARSHIP OF FACULTY DEVELOPMENT
}

\section{Mark Potter, Metropolitan State College of Denver}

This chapter critically examines the scholarship of faculty development. Using a typology adapted from one developed to understand the scholarship of teaching and learning, I reflect on the primary currents identifiable in the literature. Much of what is published in the field of faculty development consists of descriptions of the development and assessment of particular programs. One approach that is largely missing is the metastudy or review of prior studies that can serve to preserve the findings of scholar-practitioners.

As advice to new faculty developers, Neal and Peed-Neal (2009) wrote in a recent volume of To Improve the Academy (TIA) that "faculty development is a craft that must be mastered largely experientially, through imitation, observation, and trial and error, like bartending or dogwalking" (p. 15). I would add that just as with teaching, reading and reflection are essential components of the process of grounding oneself in the field. As a new faculty developer who has entered the field from the ranks of faculty, I have taken the time over the past year and a half to immerse myself in both the scholarship of teaching and learning (SoTL) and the scholarship of faculty development. The comments that follow reflect my ongoing personal grounding and the perspective I have developed toward the scholarship of faculty development.

By several measures, SoTL has matured as a field since the early 1990 s. Leaders in the field continue to write of the challenges that remain, particularly in ensuring that SoTL is valued as a form of scholarship on a par with disciplinary research and discovery. Still, when contrasted with the considerably more "adolescent" scholarship of faculty development, SoTL appears as a relatively mature field. The much less formed and smaller body of scholarship of faculty development does not, for example, benefit 
from the impressive number of journals that publish SoTL work; it does not generate the numerous national and international conferences that SoTL does, and, perhaps most interesting as an indicator, scholars have not yet analyzed this body of literature with the same critical eye they have brought to the SoTL.

Since Boyer's (1990) call for the inclusion of a scholarship of teaching as one of four types of scholarship, subsequent refinement of his argument, along with ongoing critical review of the field, have elevated SoTL to a recognized form of scholarship. Some critical reviews have included attempts to establish typologies through which to view the literature (Nelson, 2003; Weimer, 2006). Weimer lists several benefits that accrue from establishing a typology of pedagogical research (her term for SoTL), including development of a better understanding of the literature in question, the elaboration of an operational definition of the field, the establishment of points of comparison to other types of scholarship that open the way for evaluation, and the elaboration of the range of options accessible to scholars interested in the genre. Although hers is only one of several typologies of the scholarship of teaching and learning, Weimer provides one of the clearest explanations of why to approach the body of scholarship with categories and types in mind.

The critical perspective that Weimer (2006) and others have brought to SoTL can be applied with similar objectives to the scholarship of faculty development. In the process, and specifically by proposing a typology of works that comprise the field, I hope that we can gain a better sense of the parameters and direction of the field along with its strengths and weaknesses. Thus, I begin this undertaking by distinguishing some broad similarities and differences between SoTL and the scholarship of faculty development.

\section{Comparison of Literatures}

Certain parallels between the two bodies of scholarship are readily apparent. Both build on entry points for inquiry that cause discomfort among faculty. The following oft-quoted passage from Randy Bass (1999) describing the challenges of SoTL applies equally well to the scholarship of faculty development:

One telling measure of how differently teaching is regarded from traditional scholarship or research within the academy is what a difference it makes to have a "problem" in one versus the other. In scholarship and research, having a "problem" is at the heart of the investigative process; it is the compound of the generative questions around which all creative and productive activity revolves. But in one's teaching, a 
"problem" is something you don't want to have, and if you have one, you probably want to fix it. Asking a colleague about a problem in his or her research is an invitation; asking about a problem in one's teaching would probably seem like an accusation. Changing the status of the problem in teaching from terminal remediation to ongoing investigation is precisely what the movement for a scholarship of teaching is all about. (p. 1)

Similarly, in faculty development, it may well be perceived that problems are things to steer around, manage through, or fix. Yet they can also be, as Bass points out with regard to teaching, the entry points of scholarly inquiry.

Like SoTL, characterized by Weimer (2006) as a scholarship of practitioners, the articles and books that comprise faculty development scholarship are produced by practitioners (faculty developers) studying aspects of higher education relevant to their day-to-day work. Thus, both scholarships are distinct from educational research, which is driven by discipline-based questions and said to be further removed from practice (Weimer, 2006). Consequently both SoTL and faculty development scholarship are heavily instrumental in nature. Shulman (2000) credits SoTL for engaging in three areas: professionalism, pragmatism, and policy. Kreber (2005), however, criticizes SoTL for what she sees as an imbalance toward instrumentalism: "Within the discourse on the scholarship of teaching, we read, hear, and certainly learn much about how to teach certain concepts better, but relatively little about the kinds of learning experiences we hope students will have during their college and university years and why we believe certain experiences are more valuable than others" (p. 391). She would like to see a greater emphasis instead on "critical engagement with the purposes and goals of higher education and, by extension, the undergraduate curriculum" (p. 391). The study presented in this chapter explores, among other questions, where the balance between instrumentalism and critical engagement lies in the scholarship of faculty development.

One significant difference between the two bodies of literature stems from the organizational realities within the academy. Nearly all faculty are engaged in teaching within their disciplinary contexts. A much narrower cadre of professionals is committed to faculty development as practitioners, and while differences of style and sets of strengths may distinguish practitioners, there is not the variety of disciplinary perspectives from which teaching faculty and SoTL practitioners approach their craft. So whereas the body of literature in faculty development does not benefit from the widely diverse perspectives that characterize SoTL, it does not suffer from the fracturing that characterizes SoTL, wherein it is common 
for teaching faculty to limit the already modest amounts of reading they do in the field to articles appearing in journals specific to their disciplines (Weimer, 2006).

Whereas scholars have approached SoTL with a broadly critical perspective and have succeeded thereby in clarifying its parameters, no such perspective has developed with regard to the scholarship of faculty development. I therefore begin with a brief discussion of the general parameters of this literature before adapting and applying a typology and beginning a more systematic review of its main features.

\section{Parameters of the Scholarship of Faculty Development}

Faculty development as a practice differs from institution to institution, depending on local needs and culture, and thus it lacks a standard definition that unifies it across higher education (Davis et al., 2003). Moreover, there is no single statement of qualities, standards, or mission around which the scholarship that stems from the practice has coalesced. Just as a review of individual practices can shape the broad understanding of what faculty development is (King \& Lawler, 2003), so too can we draw from a review of the scholarship to identify common topical features that shape the outlines of the literature. Here I draw from frequently cited works to establish these parameters. As expected, the practice and the scholarship are closely aligned. Topical features include:

- An emphasis on instructional development, including course design and pedagogy to advance student learning (for example, Bean, 2001; Fink, 2003; Weimer, 1990).

- A commitment to the values of reflection, change, and improvement, with an understanding that faculty operate along a developmental continuum as scholar-teachers, much as students do as learners (for example, Gelmon \& Agre-Kippenhan, 2002; Robertson, 1999; Weimer, 2002; Weston \& McAlpine, 2001).

- Inclusion of organizational development as integral to promoting faculty development, satisfaction, and vitality (for example, Bland \& Schmitz, 1990; Fink, 2003; Ouellett, 2005; Weimer, 1990).

\section{Methodology}

In contrast to Weimer (2006), who spent decades reviewing pedagogical literature prior to writing her analysis of that field, my approach to this study has been to pursue an intentional and systematic literature review within 
distinct limits and undertaken in a far more compressed time frame within the year and a half that I have been a faculty developer. My original ambition had me setting off to read all faculty development articles from the past ten years published in TIA and the Journal of Faculty Development (JFD), arguably the two most prominent journals that have as their mission to publish in the field of faculty development. TIA publishes for an audience of "faculty development and organizational development professionals, administrators and consultants" (Call for Manuscripts, 2009, unpublished). The JFD publishes manuscripts "related to issues in professional development, higher education pedagogy, curriculum, leadership, program design and implementation, and evaluation and assessment" (Journal of Faculty Development, 2009). From this relatively broader range of topics found in the latter, I deselected works more closely related to SoTL or to disciplinedriven education and leadership studies in order to include in this study only works that I considered practitioner scholarship on topics related to faculty development. No such selection was necessary from among the articles published in TIA.

Such an undertaking quickly proved too great while I was also building a faculty development program to meet the needs of my institution, and I did not complete the entire decade's worth of reading. For this study, I include in my analysis all 114 articles published in TIA from 2000 to 2005 (volumes 18 to 22) and 2009 (volume 27). From the JFD I include 40 articles published during overlapping years, 2001 to 2004 (volumes 18 and 19) and 2009 (volume 23). Because I do not seek to trace changes over time, the gap in my reading between the years 2005 and 2008 should not affect my findings. Nonetheless, when it became clear that I would not complete the decade, I included the 2009 articles in my reading to verify that there were not recent changes to the field that I might otherwise overlook. My sample is sufficiently large, I believe, to be broadly representative of the decade as a whole in the field.

I have adapted the five major groups from Nelson's (2003) typology of SoTL works to construct my own parallel typology of the scholarship of faculty development. Table 21.1 captures this adaptation.

Several dimensions characterize faculty development literature, and so along with the five groups defined in Table 21.1, I also read for two additional attributes: the purpose of the article (Is it instrumental in its purpose, or is it a critical/theoretical analysis?) and methodology (Is it descriptive, reflective, synthetic, or [quasi-] experimental?). In many cases, these additional attributes can be inferred by the group in which the article is placed. We can expect, for example, that an article in group 2 follows a reflective methodology. Most reports on particular programs (group 1) 


\section{Table 2r.I Typologies of SoTL and the Scholarship of Faculty Development}

\begin{tabular}{lll}
$\begin{array}{l}\text { Group } \\
1\end{array}$ & $\begin{array}{l}\text { Nelson's SoTL Typology } \\
\text { Reports on particular classes }\end{array}$ & $\begin{array}{l}\text { Adapted Typology of Scholar- } \\
\text { ship of Faculty Development } \\
\text { Reports on particular pro- } \\
\text { grams, collaborations, or } \\
\text { projects }\end{array}$ \\
2 & $\begin{array}{l}\text { Reflections on several years of } \\
\text { teaching experience, implicitly } \\
\text { or explicitly informed by } \\
\text { other SoTL }\end{array}$ & $\begin{array}{l}\text { Reflections on faculty develop- } \\
\text { ment experience, implicitly or } \\
\text { explicitly informed by } \\
\text { other faculty development } \\
\text { scholarship }\end{array}$ \\
3 & $\begin{array}{l}\text { Larger contexts: Comparisons } \\
\text { of courses and comparisons of } \\
\text { student change across time }\end{array}$ & $\begin{array}{l}\text { Larger contexts: Trends in fac- } \\
\text { ulty development and compari- } \\
\text { sons of programs }\end{array}$ \\
4 & $\begin{array}{l}\text { Learning science } \\
\text { Summaries and analyses of sets } \\
\text { of prior studies }\end{array}$ & $\begin{array}{l}\text { Adult development studies } \\
\text { summaries of prior studies }\end{array}$ \\
\hline
\end{tabular}

Source: Adapted from Nelson (2003).

are instrumental in purpose and descriptive in method, and some studies of larger contexts (group 3) are instrumental in purpose, while others provide critical or theoretical analyses.

The process of assigning groups and determining attributes hinged on the judgment and reflection that I brought to my reading of the articles. My methodology is not even quasi-experimental, and my placement of works into categories is not intended to render replicable results but rather to invoke thematic conclusions. Using my own typology, I consider this work to belong to group 5 (metastudy or review or summary of prior studies), mostly descriptive in methodology (though with considerable reflection brought to bear), and with a purpose more of providing critical analysis than of offering instrumental "takeaways."

\section{Findings}

Table 21.2 presents the aggregate placement of articles into the five groups of the proposed typology. Together, groups 1 and 3 (reports on particular programs and studies of larger contexts) dominate the faculty development literature, amounting to approximately 90 percent of all articles published, with the number of articles in group 1 surpassing those 
Table 2 r.2 Assignment of Reviewed Literature to the Typology of the Scholarship of Faculty Development

$\begin{array}{lrr}\text { Group } & \text { Number } & \text { Percentage } \\ 1 & 90 & 58.4 \\ 2 & 9 & 5.8 \\ 3 & 48 & 31.2 \\ 4 & 6 & 3.9 \\ 5 & 1 & 0.7 \\ n & 154 & 100.0\end{array}$

in group 3 by nearly a factor of two. Reflections on experience and adult development studies comprise a much more modest proportion of the articles, together amounting to around 10 percent, while metastudies and literature reviews barely register in the sample.

With regard to the two additional attributes for which I read, purpose and methodology, tables 21.3 and 21.4 indicate that four-fifths of the articles are instrumental in purpose, reflecting again the dominance of groups 1 and 3, while the most practiced methods, in descending order, are descriptive, descriptive with assessment, and synthetic.

Method is the one dimension where I observed a notable difference between articles from the two publications. Whereas (quasi-)experimental methods are removed from the central trends of this literature, they are found more often in JFD (approximately 25 percent of articles reviewed) than in TIA (approximately 5 percent of articles reviewed). The JFD has on average published roughly half the number of articles each year as TIA.

Table 21.3 Purpose of Faculty Development Literature, by Group

$\begin{array}{lcc}\text { Group } & \text { Critical or Theoretical } \\ 1 & 89 & \text { Analysis } \\ 2 & 2 & 1 \\ 3 & 35 & 7 \\ 4 & 0 & 13 \\ 5 & 0 & 6 \\ n & 126 & 1 \\ & & 28\end{array}$




\section{Table 21.4 Methodology of Faculty Development Literature, by Group}

\begin{tabular}{llllll} 
& & \multicolumn{5}{l}{$\begin{array}{l}\text { Synthesis } \\
\text { Descrip- } \\
\text { tive with }\end{array}$} & $\begin{array}{l}\text { (with or } \\
\text { Without }\end{array}$ & $\begin{array}{c}\text { Experi- } \\
\text { mental }\end{array}$ & Reflective \\
1 & Descriptive & Assessment & Reflection) & ment \\
2 & 41 & 38 & 0 & 7 & 4 \\
3 & 0 & 0 & 1 & 0 & 8 \\
4 & 12 & 1 & 21 & 10 & 4 \\
5 & 0 & 0 & 5 & 0 & 1 \\
$n$ & 0 & 0 & 1 & 0 & 0 \\
& 53 & 39 & 28 & 17 & 17
\end{tabular}

Had I read in the JFD over the same years as I did from TIA, I estimate that my sample would have included sixty articles from the journal, rather than the forty that it does, and, by extrapolation, articles that follow an experimental method would have numbered roughly twenty-five, or 16 percent of the sample. Even with such a correction, the experimental method would still remain behind description and description with assessment as the main methods within the scholarship of faculty development.

\section{Discussion}

The typology proposed for this study accommodates the range of faculty development literature that I reviewed from the two primary outlets of the field. Given these results, and because this typology parallels so closely Nelson's (2003) typology of SoTL, I proceed through this discussion informed by the similarities between the two fields; where observations, critiques, and defenses have been directed toward SoTL, I consider them with respect to the scholarship of faculty development.

Although an advocate of SoTL, Kreber (2005) has nonetheless critiqued that body of scholarship for its strong inclination toward an instrumental approach. Her premise is that "the academy needs to begin to ask more critical questions if the scholarship of teaching movement is to have a lasting, positive and practical impact on our colleges and universities, as well as on the wider society" (pp. 391-392). One's first impression of the scholarship of faculty development, with fully fourfifths of the articles characterized as instrumental in purpose, might be 
that this criticism applies to it as well. This is indeed a literature that is highly pragmatic and weighted toward meeting generally agreed-on goals rather than questioning or critiquing those goals. Kreber (2003) herself extends her critique to the work of faculty development and offers her vision of how it can move beyond "instrumental learning" and focus instead on addressing the question "of what kind of learning to promote" (p. 296). My reading, however, leads me to argue that Kreber's standard is not the sole criterion by which a contribution to the field can be critical, rather than instrumental, in its purpose. I have applied a broadened conception of what constitutes a critical study to include those that seek to shift the paradigm of instruction in our colleges and universities from instructor centered to learner centered (Barr \& Tagg, 1995), and those that seek to reconsider and reposition the role of faculty development within institutions of higher education. The common feature, even accounting for this broadened conception of the critical and theoretical, is that the objectives of the studies extend beyond aiding practical effectiveness to instead bringing change to educational culture.

Specific examples from the sample of articles reviewed for this study illustrate this broader view of what it means to be critical rather than instrumental. Angelo (2001) proposes guidelines for promoting transformative ideas in higher education, including Barr and Tagg's (1995) "learning paradigm." McKinney (2002), alternatively, uses synthesis and reflection to probe the relationship between instructional development, which she considers one component of more general faculty development, and teaching and learning. Both types of "critical" approaches to faculty development posit faculty development initiatives as if they were, as Lieberman (2005) advocates, laboratories for learning organizations intent on a culture of self-examination, evidence, and improvement.

Furthermore, it would be a mistake to dismiss the overwhelming majority of works that appear in faculty development literature as less serious or significant simply because their authors' interests are pragmatic and instrumental. Within groups 1 and 3, where nearly all of the instrumental approaches to faculty development are found, the very purpose of the programs described is often to effect change. Bonilla and Palmerton (2001), for example, describe a focus group approach to learning whether race and gender were real issues in the classroom for both students and faculty, and among their findings was the identification of several troubling issues along with calls to action. DeZure (2003), writing in the aftermath of the terrorist attacks of September 11, 2001, suggests specific steps that faculty developers can take to promote internationalization while acknowledging the urgent need for undergraduate education to 
focus its efforts on the development of global competencies. From these examples, it is clear that the overlap between two scholarly foci-faculty development and organizational development in higher educationmeans that even instrumental approaches to faculty development have the potential to effect systemic change in organizations. Within what is predominantly a practitioner literature, therefore, a critical or theoretical approach is not necessary to bring about systemwide changes or even paradigm shifts.

Kreber (2005) issued her critique of SoTL in the midst of a broader discussion regarding its "scholarly" quality. Following Boyer's (1990) broadened use of scholarship to recognize that "knowledge is acquired through research, through synthesis, through practice, and through teaching" (p. 24), Andresen (2000) became concerned that the term "may be degenerating into a ubiquitous buzzword" and asked, "What might scholarly teaching look like?" (pp. 138, 142). Weimer (2006) defends the scholarly qualities of pedagogical literature by referencing what she identifies as a shared understanding of the qualities that make a practitioner scholarship viable. Those qualities, she argues, are dissemination of findings among peers and colleagues, creation or enhancement of knowledge and insight, relevant findings with practical application, and the construction of a body of knowledge through incorporation of other past findings. Wisdom of practice, she adds, opens the door to description, outcomes assessment, and reflection-not the strictly hard scientific or experimental methodologies that are commonly expected from the scholarship of discovery-as appropriate methodologies.

These discussions surrounding SoTL raise a similar question with regard to the scholarship of faculty development: Is it indeed a coherent and viable body of scholarship? When measured against the four criteria Weimer described, my answer is mostly yes. The works that I encountered unambiguously satisfy the first three of the criteria. This is a body of scholarship in that it is disseminated, with published, peer-reviewed articles and books as the primary format. The ideas and findings contained within the literature establish and enhance our knowledge, and the especially instrumental orientation of the literature underscores its relevance to practical application.

Less immediately clear is whether this scholarship builds intentionally and consistently on past findings. Throughout my review of the literature, several topical strands and clusters of programs with shared goals surfaced. These include, as examples, programs in support of early career faculty development, programs in support of SoTL, and descriptions of particular approaches to strategic planning or positioning faculty development 
efforts within an institution. Articles solely on the topic of mentoring new faculty, for example, number 6 within my sample, comprise only a subset of articles on the broader topic of early career faculty development. Within such instrumental and descriptive articles (mostly of type 1), numerous as they are, it is not uncommon to find requisite references to seminal works but little attention paid to explaining how the programs being proposed compare with those previously described in the literature as advancing shared goals.

While it might be unfair to expect the authors of each such successive article to provide a full inventory of previously described programs that share common goals, there is ample room within this literature for more works belonging to group 5 (metastudies or reviews and summaries of prior studies), of which I identified a mere 1 out of 154 articles. Both thematically oriented review articles and metastudies can serve to preserve, and evaluate within a broader context, the findings of practitioners who have written of their programs, innovations, and approaches and whose ideas risk becoming lost within the growing body of publications. Indeed, as I complete this study, I am encouraged to see an example of just such an approach to the scholarship of faculty development by Lottero-Perdue and Fifield (2010) in the most recent issue of TIA on the topic, no less, of faculty mentoring.

\section{Conclusion}

As should be clear by this point, reviews and critiques of the scholarship of faculty development are less common than they are of SoTL. The one such study that I identified in my reading is McKinney's (2002) review of the recent literature in instructional development in higher education. She writes, as I have found, that "it is not surprising that much of the writing in this area is still descriptive" (p. 231). She does not call for a greater emphasis on critical and theoretical analyses but rather asserts that "more frequent use of well-designed experiments would add to the knowledge base" (p. 232).

While my findings confirm the lesser role of the (quasi-)experimental approach, this review leads me to conclude that the greatest impact from this practitioner scholarship, oriented by its nature to produce descriptive works for instrumental purposes, can come from scholar-practitioners broadly incorporating one another's ideas and findings in a more intentional and consistent manner, building on what is known to be effective in specific contexts, and thereby creating a body of knowledge that is tightly connected to the efforts and accomplishments of the past. By 
doing so, we will achieve what Andresen (2000) identifies as one of the quintessential scholarly attributes, whereby "scholarly knowing, about anything whatsoever, is never final, but always subject to public scrutiny, discussion, reconsideration, and perhaps change" (p. 141).

\section{REFERENCES}

Andresen, L. W. (2000). A useable, trans-disciplinary conception of scholarship. Higher Education Research and Development, 19(2), 137-153.

Angelo, T. A. (2001). Doing faculty development as if we value learning most: Transformative guidelines from research to practice. In D. Lieberman \& C. Wehlburg (Eds.), To improve the academy: Vol. 19. Resources for faculty, instructional, and organizational development (pp. 225-237). San Francisco: Jossey-Bass/Anker.

Barr, R. B., \& Tagg, J. (1995). From teaching to learning-A new paradigm for undergraduate education. Change, 27(6), 12-25.

Bass, R. (1999). The scholarship of teaching: What's the problem? Inventio: Creative Thinking About Learning and Teaching, 1(1), 1-10.

Bean, J. C. (2001). Engaging ideas: The professor's guide to integrating writing, critical thinking, and active learning in the classroom. San Francisco: Jossey-Bass.

Bland, C., \& Schmitz, C. (1990). An overview of research on faculty and institutional vitality. In J. Schuster, D. Wheeler, \& Associates, Enhancing faculty careers: Strategies for development and renewal (pp. 41-61). San Francisco: Jossey-Bass.

Bonilla, J. F., \& Palmerton, P. R. (2001). A prophet in your own land? Using faculty and student focus groups to address issues of race, ethnicity, and gender in the classroom. In D. Lieberman \& C. Wehlburg (Eds.), To improve the academy: Vol. 19. Resources for faculty, instructional, and organizational development (pp. 49-68). San Francisco: Jossey-Bass/Anker.

Boyer, E. L. (1990). Scholarship reconsidered: Priorities of the professoriate. Princeton, NJ: Carnegie Foundation for the Advancement of Teaching.

Davis, G., Foley, B. J., Horn, E., Neal, E., Redman, R., \& Van Riper, M. (2003). Creating a comprehensive faculty development program. Journal of Faculty Development, 19(1), 19-28.

DeZure, D. (2003). Internationalizing American higher education: A call to thought and action. In C. Wehlburg \& S. Chadwick-Blossey (Eds.), To improve the academy: Vol. 21. Resources for faculty, instructional, and organizational development (pp. 40-55). San Francisco: Jossey-Bass/Anker.

Fink, L. D. (2003). Creating significant learning experiences: An integrated approach to designing college courses. San Francisco: Jossey-Bass. 
Gelmon, S. B., \& Agre-Kippenhan, S. (2002). A developmental framework for supporting evolving faculty roles for community engagement. Journal of Public Affairs, 6, 161-182.

Journal of Faculty Development. (2009). Journal of Faculty Development, 23(3), 3. King, K. P., \& Lawler, P. A. (2003). Best practices in faculty development in North American higher education: Distinctions and dilemmas. Journal of Faculty Development, 19(1), 29-36.

Kreber, C. (2003). Embracing a philosophy of lifelong learning: Starting with faculty beliefs about their role as educators. In C. Wehlburg \& $\mathrm{S}$. ChadwickBlossey (Eds.), To improve the academy: Vol. 21. Resources for faculty, instructional, and organizational development (pp. 288-301). San Francisco: Jossey-Bass/Anker.

Kreber, C. (2005). Charting a critical course on the scholarship of university teaching movement. Studies in Higher Education, 30(4), 389-405.

Lieberman, D. (2005). Beyond faculty development: How centers for teaching and learning can be laboratories for learning. In A. Kezar (Ed.), New directions in higher education: No. 131. Organizational learning in higher education (pp. 87-98). San Francisco: Jossey-Bass.

Lottero-Perdue, P. S., \& Fifield, S. (2010). A conceptual framework for higher education faculty mentoring. In L. B. Nilson \& J. E. Miller (Eds.), To improve the academy: Vol. 28. Resources for faculty, instructional, and organizational development (pp. 37-62). San Francisco: Jossey-Bass.

McKinney, K. (2002). Instructional development: Relationships to teaching and learning in higher education. In D. Lieberman \& C. Wehlburg (Eds.), To improve the academy: Vol. 20. Resources for faculty, instructional, and organizational development (pp. 225-237). San Francisco: Jossey-Bass/Anker.

Neal, E., \& Peed-Neal, I. (2009). Experiential lessons in the practice of faculty development. In L. B. Nilson \& J. E. Miller (Eds.), To improve the academy: Vol. 27. Resources for faculty, instructional, and organizational development (pp. 14-31). San Francisco: Jossey-Bass.

Nelson, C. (2003). Doing it: Examples of several of the different genres of the scholarship of teaching and learning. Journal on Excellence in College Teaching, 14(2), 85-94.

Ouellett, M. L. (Ed.). (2005). Teaching inclusively: Resources for course, department and institutional change in higher education. Stillwater, OK: New Forums Press.

Robertson, D. L. (1999). Professors' perspectives on their teaching: A new construct and developmental model. Innovative Higher Education, 23(4), 271-294.

Shulman, L. (2000). From Minsk to Pinsk: Why a scholarship of teaching and learning? Journal of Scholarship of Teaching and Learning, 1(1), 48-53. 
Weimer, M. (1990). Improving college teaching: Strategies for developing instructional effectiveness. San Francisco: Jossey-Bass.

Weimer, M. (2002). Learner-centered teaching: Five key changes to practice. San Francisco: Jossey-Bass.

Weimer, M. (2006). Enhancing scholarly work on teaching and learning: Professional literature that makes a difference. San Francisco: Jossey-Bass.

Weston, C., \& McAlpine, L. (2001). Making explicit the development toward the scholarship of teaching. In C. Kreber (Ed.), New directions for teaching and learning: No. 86. Scholarship revisited: Perspectives on the scholarship of teaching (pp. 89-97). San Francisco: Jossey-Bass. 